\title{
Ultrahigh Radio Frequency (820-960 MHz) Identification System Affects Antioxidant Barrier in Red Blood Cell Concentrates
}

Anna Małgorzata Chabowska1, Marta Nędzi', Alina Lipska1, Anna Rogowska1, Barbara Boczkowska-Radziwon'1, Jolanta Korsak², Mateusz Dziemianczuk ${ }^{1}$ and Piotr Radziwon ${ }^{1,3 *}$

${ }^{1}$ Regional Centre for Transfusion Medicine, Bialystok, Poland

${ }^{2}$ Department of Transfusiology, Military Institute of Medicine, Warsaw, Poland

${ }^{3}$ Department of Haematology, Medical University of Bialystok, Poland

\begin{abstract}
Background and objectives: Radio frequency identification (RFID) tags have advantages over bar codes in blood management system. Ultra-high frequency (UHF) RFID technology (820-960 MHz) in many ways has more advantages than high frequency (HF) RFID (13.56 MHz). The aim of our study was the evaluation of the effects of UHF RFID in comparison to HF RFID radiation on quality markers of RBC and on the oxidoreductive balance in RBC stored in containers labelled with RFID tags.
\end{abstract}

Materials and methods: Ten RBC units were split into three components, one control unit-marked with bar code and two test units labeled with RFID tags - one operating on UHF and the second on HF radio waves. All units were stored at $2-6^{\circ} \mathrm{C}$ for 35 days. The test groups were exposed to radio waves continuously during storage. The quality parameters as well as concentration of malondialdehyde (MDA), and activities of superoxide dismutase, glutathione peroxidase and glutathione reductase were measured.

Results: The degree of hemolysis and the concentration of $\mathrm{K}+$ were statistically significant higher on $35^{\text {th }}$ day of storage in RBC labelled with UHF RFID tags compare to control and HF RFID groups. On the $35^{\text {th }}$ day of storage the concentration of MDA was statistically significant higher and the activities of oxidoreductive enzymes were statistically significant lower in the UHF group compare to control and HF groups.

Conclusion: UHF RFID tags affect oxidoreductive balance in RBC and may lead to eryptosis. The approval of UHF RFID system for blood components needs further studies.

Keywords: RFID; Radio waves; Erythrocytes; Antioxidant barrier; Tag

\section{Introduction}

In recent years, there is growing interest in radio frequency identification (RFID) technology as a complement to bar code technology in transfusion medicine. Several blood centers and hospitals have tested the utilization of radio frequency identification (RFID) as a means of enhancing tracking, monitoring, labeling, and storage in the blood transfusion supply chain, and have found it to be very promising [1]. With the help of built-in memory, RFID tag can carry defined information on the blood component been tagged. RFID can read multiple numbers of tags simultaneously even in adverse light conditions [2]. By exploiting these characteristics, RFID can be employed in healthcare especially in transfusion medicine.

RFID system is composed of transponder tags, readers, and a hardware system to which information is written. There are three different frequency ranges on which RFID can work. Low frequency (LF) bands typically work at frequencies of $125-134 \mathrm{kHz}$. High Frequency (HF) bands operate at $13.56 \mathrm{MHz}$. This is the global ISOstandardized frequency, and is widely accepted for use in the healthcare industry. Ultra High Frequency (UHF) works at 850-900 MHz. These are the most expensive tags, possessing the best ranges and transferring data at the fastest. UHF RFID tags are better than HF RFID tags in either in the read and write times, distance from tag to reader, and the number of targets that can be read simultaneously or on the environmental adaptability and anti-interference ability. Particularly UHF RFID tags are not affected by ultralow temperature. It makes them more suitable for applications in the management of blood components.

However, UHF licenses vary in allowance due to health and safety issues. The International Society for Blood Transfusion (ISBT) working party on RFID has recommended $\mathrm{HF}(13.56 \mathrm{MHz})$ as the international standard for transfusion medicine but the standards for UHF RFID can vary from country to country $[2,3]$. RFID technology is used mainly for identification of valuable commodities such as blood components albeit it can support additional functionalities like monitoring temperature. Even though the effects of radio frequency (RF) electromagnetic radiation on biologics due to temperature changes are relatively well understood, there are few studies in the literature about other effects of this kind of radiation that can occur without a noticeable change in temperature.

There is little known about the effect of radio waves on oxidative stress and there are no data on the RFID effect on oxidant-antioxidant equilibrium in blood components. The aim of our study was the evaluation of the effects of $850-900 \mathrm{MHz} R$ R radiation in comparison to $13.56 \mathrm{MHz} \mathrm{RF}$ radiation on quality markers of $\mathrm{RBC}$ and on the intensity of lipid peroxidation and activity of antioxidant barrier enzymes in RBC stored in containers labelled with RFID tags.

*Corresponding author: Piotr Radziwon, Regional Centre for Transfusion Medicine, Białystok 15-950, ul. M. Skłodowskiej-Curie 23, Poland, Tel: +48 857447002; Fax: +48 857447133; E-mail: piotr.radziwon@wp.pl

Received March 18, 2018; Accepted April 13, 2018; Published April 20, 2018

Citation: Chabowska AM, Nędzi M, Lipska A, Rogowska A, BoczkowskaRadziwon B, et al. (2018) Ultrahigh Radio Frequency (820-960 MHz) Identification System Affects Antioxidant Barrier in Red Blood Cell Concentrates. J Blood Lymph 8: 213. doi:10.4172/2165-7831.1000213

Copyright: (c) 2018 Chabowska AM, et al. This is an open-access article distributed under the terms of the Creative Commons Attribution License, which permits unrestricted use, distribution, and reproduction in any medium, provided the original author and source are credited. 
Citation: Chabowska AM, Nędzi M, Lipska A, Rogowska A, Boczkowska-Radziwon B, et al. (2018) Ultrahigh Radio Frequency (820-960 MHz) Identification System Affects Antioxidant Barrier in Red Blood Cell Concentrates. J Blood Lymph 8: 213. doi:10.4172/2165-7831.1000213

Page 2 of 5

\section{Materials and Methods}

All experiments were approved by the University Bioethics Committee of the Medical University of Białystok (R-I-002/445/2012). Blood donations were conducted in accordance with the Public Blood Transfusion Service Act sanctioned in 1997. Written informed consent for this study was obtained from each blood donor.

\section{Preparation of RBCs}

Ten units of whole blood $(450 \pm 50 \mathrm{~mL})$ were collected into standard triple containers $450 / 2 \times 600 \mathrm{RW}$ (Fresenius AG, Schweinfurt, Germany) with $63 \mathrm{ml} \mathrm{CPD} \mathrm{(Citrate,} \mathrm{Phosphate,} \mathrm{Dextrose)} \mathrm{as} \mathrm{an}$ anticoagulant. Before separation of blood components, the units of blood were pre-stored for 2.5 hours at $22 \pm 2^{\circ} \mathrm{C}$. Then whole blood units were centrifuged using Roto Silenta 630RS (Hettich, Tuttlingen, Germany) with the acceleration of $4946 \mathrm{~g}$ (3926 rpm/min) for 10 minutes at $22^{\circ} \mathrm{C}$. Separation of whole blood for erythrocyte concentrate, plasma and buffy coat (BC) was made by using the automatic press Compomat G4 (Fresenius, Schweinfurt, Germany). Erythrocytes were suspended in SAGM (Saline, Adenine, Glucose, Mannitol) preservative solution $(100 \mathrm{~mL})$ which allows their storage for 42 days at $2-6^{\circ} \mathrm{C}$. RBC units (mean volume $300 \mathrm{~mL}$ ) were split into three components of an equal volume (about $100 \mathrm{~mL}$ ), one control unit and two test units. The volume of $100 \mathrm{~mL}$ was tested as it represents the smallest components stored (for pediatric use) and allows to perform our study in the worstcase scenario. The RBCs used for this study originated from separate whole blood units collected on the same day. For our study RBC units were stored at $2-6^{\circ} \mathrm{C}$ for 35 days but not for 42 days (maximum allowed storage time) as $99 \%$ of units are released for transfusion within this time.

Exposure to radio waves of RFID system Control group-10 RBCs, labelled with bar codes. Group UHF-10 RBCs, constant exposure to 915 $\mathrm{MHz}$ (UHF) radio waves. Radio frequency generators-UHF readers FEIG OBID LRU2000SLX (Weilburg-Waldhausen, Germany) with two UHF directional antennas for extended angle of radiation were placed on the shelves of refrigerator (Norcool, Łazy, Poland). Antennas were placed in a way that ensures the reading of tags located on the shelves of refrigerator. RBCs were labeled with tags of the UHF band (Chip NXP Semiconductors (Shanghai) Ltd Beijing, China). Tags were attached directly to the free surface of the container.

Tags specifications

- $\quad$ Passive tags.

- $\quad$ The memory used 512 bits, 1024 bits of memory available.

- Comply with the protocol EPC GEN II.

- Dimensions $100 \times 15 \times 0.2 \mathrm{~mm}$.

- $\quad$ Reading distance tag-reader: $3 \mathrm{~cm}-7 \mathrm{~cm}$.

- $\quad$ Operating temperature: $2^{\circ} \mathrm{C}-55^{\circ} \mathrm{C}$.

The readers have been continuously reading tags in millisecond intervals. Group HF - $10 \mathrm{RBCs}$, constant exposure to $13.56 \mathrm{MHz}$ (HF) radio waves. Radio frequency generators-readers RWM600 (NXP, Semiconductors (Shanghai) Ltd Beijing, China) with integrated HF range antenna were placed on the shelves of refrigerator (Norcool, Łazy, Poland). RBCs were labeled with the HF range tag (Chip NXP, Semiconductors (Shanghai) Ltd Beijing, China). Tags were directly attached to the free surface of the container.

Specifications of used tags
- $\quad$ Passive tags, read/write.

- The memory used 512 bits, 1024 bits of memory available.

- Comply with the ISO 15693 protocol (Icod).

- Dimensions $125 \times 35 \times 0.8 \mathrm{~mm}$.

- $\quad$ Reading distance tag-reader 3 to $20 \mathrm{~cm}$.

- Operating temperature: $-35^{\circ} \mathrm{C}$ to $+55^{\circ} \mathrm{C}$.

The readers have been continuously reading tags in millisecond intervals. All components were stored at $2-6^{\circ} \mathrm{C}$ for 35 days in refrigerators of the same manufacturer and model which were placed in separate rooms in order to avoid intergroup interference.

\section{Sample collection}

Before sampling RBC were gently mixed and samples were taken into two test-tubes (about $10 \mathrm{~mL}$ in each test tube) (without anticoagulant) for biochemical analysis and assessment of oxydoreductive balance. Samples were taken on day 0 immediately after preparation of RBC, and on day 7, 14, 21 and 35 of storage. The samples were centrifuged at $3000 \times \mathrm{g}$ for $10 \mathrm{~min}$. After aspiration of plasma the erythrocytes were washed with $0.9 \% \mathrm{NaCl}$ solution. Erythrocytes were hemolysed by adding triple volume of distilled water. The $\mathrm{Hb}$ concentration in the hemolysate was measured by Pentra 80 ABX (Horiba Diagnostic, France) using the Drabkin method [4-8].

\section{Determination of Lipid Peroxidation and Antioxidant Enzyme Activity}

\section{Lipid peroxidation}

As a marker of lipid peroxidation malonyldialdehyde (MDA) concentration was determined in isolated erythrocytes using the method described by Buege and Aust [9]. This method is based on reaction with thiobarbituric acid (TBA) and is used for the production of a color MDA-TBA complex in acidic conditions at an elevated temperature. Erythrocytes were incubated in the presence of $20 \%$ TCA at $4^{\circ} \mathrm{C}$ for $1 \mathrm{~h}$, and then centrifuged at $1000 \times \mathrm{g}$ for $5 \mathrm{~min}$. The obtained supernatant in the presence of $0.26 \mathrm{M}$ TBA was heated for 15 min at $100^{\circ} \mathrm{C}$. Absorbance measurement was performed at $\lambda=532 \mathrm{~nm}$ (Spectrophotometer Epoll-20, Poll Ltd., Poland) and was compared with first control sample (20\% TCA, $0.26 \mathrm{M} \mathrm{TBA)}$ and second control sample (20\% TCA and erythrocytes). Amplification of peroxidation during the assay was stopped by the addition of the chain-breaking antioxidant butylated hydroxytoluene $(10 \mu \mathrm{L}$ of $2 \mathrm{mM} / \mathrm{L}$ per $1 \mathrm{~mL}$ of $\mathrm{RBC}$ ). The concentration of MDA in a sample was calculated using a molar extinction coefficient $1.56 \times 10^{6} \mathrm{~mol}^{-1} \mathrm{~cm}^{-1}$ and expressed in nanomoles per gram of hemoglobin [nmol/gHb].

\section{Superoxide dismutase activity (SOD)}

Activity of SOD was determined using the method of Sykes et al. [10]. Previously prepared hemolysates were used to measure the activity of SOD in the tested samples. Three and half $\mathrm{ml}$ of bidistilled water chilled to $+4^{\circ} \mathrm{C}$ were added to $0.5 \mathrm{ml}$ of the hemolysate, followed by $1 \mathrm{ml}$ of $96 \%$ ethanol and $0.6 \mathrm{ml}$ of chloroform. The mixture was shaken and then centrifuged for 10 minutes at $4200 \times \mathrm{g}$. The aqueous supernatant containing the enzyme was used in the respective reaction mixture. The reaction mixture contained $1.8 \mathrm{~mL}$ carbonate buffer $(0.05$ $\mathrm{mol} / \mathrm{L}), 100 \mu \mathrm{L}$ of supernatant and $100 \mu \mathrm{L}$ of adrenaline $(18 \mathrm{mg} / 10 \mathrm{~mL})$. The increase in absorbance at $490 \mathrm{~nm}$ (Spectrophotometer Epoll-20, Poll Ltd., Poland) $\left(\mathrm{T}=30^{\circ} \mathrm{C}\right)$ from zero during 2 min was compared 
Citation: Chabowska AM, Nędzi M, Lipska A, Rogowska A, Boczkowska-Radziwon B, et al. (2018) Ultrahigh Radio Frequency (820-960 MHz) Identification System Affects Antioxidant Barrier in Red Blood Cell Concentrates. J Blood Lymph 8: 213. doi:10.4172/2165-7831.1000213

Page 3 of 5

with control in which the red blood cells were replaced by $0.9 \% \mathrm{NaCl}$. The method involves the enzyme-induced inhibition of adrenalin selfoxidation to adrenochrome in acidic conditions accompanied by the generation of superoxide radical $\left(\mathrm{O}_{2}^{-*}\right)$ as an intermediate product. The activity of SOD was measured in one-minute time intervals based on changes in absorbance $\left(\lambda=490 \mathrm{~nm}, \mathrm{~T}=30^{\circ} \mathrm{C}\right)$ in a sample containing the enzyme as compared to the analogous time absorbance changes in control samples. The activity of SOD in study samples was expressed in adrenaline units [U/gHb].

\section{Glutathione peroxidase activity (GSH-Px)}

The activity of GSH-Px was determined using the method described by Paglia and Valentine [11]. The reaction mixture contained $100 \mu \mathrm{L}$ of NADPH solution $(8.4 \mathrm{mM} / \mathrm{L}), 10 \mu \mathrm{l}$ glutathione reductase (GSSG-R) $(100 \mathrm{U} / \mathrm{mL}), 10 \mu \mathrm{L}$ sodium azide $(1.125 \mathrm{~mol} / \mathrm{l}), 100 \mu \mathrm{L}$ glutathione $(0.02$ $\mathrm{mol} / \mathrm{L})$ filled with phosphate buffer $(0.05 \mathrm{~mol} / \mathrm{L})$ up to the volume of $2.8 \mathrm{~mL}$ and $100 \mu \mathrm{L}$ hemolysate. The enzymatic reaction was initiated by addition of $100 \mu \mathrm{L}$ of $0.022 \mathrm{~mol} / 1 \mathrm{H}_{2} \mathrm{O}_{2}$. In the presence of GSSG-R and $\mathrm{NADPH}$ the oxidized glutathione (GSSG) is immediately converted to the reduced form with a concomitant oxidation of NADPH to NADP+. The samples were assayed by UV Visible spectrophotometer (Epoll-20, Poll Ltd., Poland) at a wavelength of $340 \mathrm{~nm}$. The activity of GSH-Px was expressed in international units [ $\mathrm{U} / \mathrm{gHb}]$.

\section{Glutathione reductase activity}

The activity of GSSH-R was determined using the method described by Mize and Langdon [12]. The reaction mixture contained $0.5 \mathrm{~mL}$ potassium phosphate solution $(\mathrm{pH} 7 ; 0.02 \mathrm{M}), 0.5 \mathrm{~mL}$ EDTA $(0.33 \mathrm{mM}), 0.5 \mathrm{~mL}$ GSSH $(7 \mathrm{mM} / \mathrm{L})$ and $200 \mu \mathrm{L}$ of NADPH solution $(8.4 \mathrm{mM} / \mathrm{L})$ and $0.04 \mathrm{~mL}$ hemolysate. The rate of change of extinction at $340 \mathrm{~nm}$ was determined by UV Visible spectrophotometer (Epoll-20, Poll Ltd., Poland) for one minute at $37^{\circ} \mathrm{C}$ and was compared with control (Tris-HCl buffer). The activity of GSSH-R was expressed in international units [IU].

\section{Hemogram}

Complete hemogram: hemoglobin, hematocrit, total count of WBC, total count of RBC, platelet count, mean corpuscular volume, mean corpuscular hemoglobin, and mean corpuscular hemoglobin concentration were estimated by Pentra 80ABX (Horiba Diagnostic, France) automated cell counter. Concentration of free hemoglobin was measured using Plasma Low HB System (Hemocue, Sweden) according to the manufacturer's recommendation and the degree of hemolysis-the percent of free hemoglobin in relation to the total was calculated using the formula: $(100-\mathrm{Hct}) \times$ plasma $\mathrm{Hb}(\mathrm{g} / \mathrm{dL}) /$ total $\mathrm{Hb}(\mathrm{g} / \mathrm{dL})$, where $\mathrm{Hct}$ is hematocrit and $\mathrm{Hb}$ is hemoglobin concentration.

\section{Electrolytes, pH and lactate dehydrogenase}

The concentration of potassium, sodium and chloride ions were determined using the ISE series apparatus BioMaxima (Poland) and the concentration of glucose was determined by spectrophotometry using the Konelab 60iSE apparatus (BioMerieux, France). $\mathrm{pH}$ value was determined at $22^{\circ} \mathrm{C}$ with a $\mathrm{pH}$-meter Suntex SP-701 (Poland). The activity of LDH was assessed using Cobas c311 System (Roche, Switzerland).

\section{Statistics}

In the statistical analysis, there was no normal distribution of quantitative variables analyzed, which was checked using ShapiroWilk test. Comparing the quantitative variables without the normal distribution was used nonparametric ANOVA Kruskal-Wallis Rank with the test post-hoc multiple comparisons average rank for all samples, for the three groups. Results were considered statistically significant at $p<0.05$. Elements of descriptive statistics were used to determine medians and quartiles for each parameter. Statistica 10.0 (StatSoft, Krakow, Poland) was used for statistical analyses.

\section{Results}

The degree of hemolysis in the test and control RBC units has increased with time of storage. On day 35 in RBC units from group UHF hemolysis degree was statistically significant higher $(\mathrm{p}<0.05)$ than in other tested RBC groups. In each study groups hemolysis degree was within the European Council criteria (lower than 0.8\%) (Table 1).

\section{Biochemical parameters}

The concentration of glucose and $\mathrm{pH}$ value has decreased during the storage period in RBC units but they were not statistically significant different between the groups. The activity of LDH has increased in the units of RBC during storage (Table 1 ). There was no statistically significant differences in the activity of LDH between treated groups. The concentration of $\mathrm{K}^{+}$has increased during storage in each study groups. On day 35 in RBC units from group UHF statistically significant higher $(\mathrm{p}<0.05)$ concentration of $\mathrm{K}^{+}$was noted in comparison to other tested groups. The concentration of $\mathrm{Na}^{+}$ions did not show statistically significant differences between the groups of RBC units during storage (Table 1).

\section{Lipid peroxidation}

The concentration of MDA in RBC units have increased with the time of storage. There were no statistically significant differences in the concentration of MDA between the groups until day 35. The concentration of MDA in the group UHF subjected to constant exposure to UHF radio waves on the $35^{\text {th }}$ day of storage was statistically significant higher than in control group and group $\mathrm{HF}(13.5 \mathrm{MHz})$ (Figure 1A).

\section{Antioxidative status biomarkers}

The activity of SOD in all groups has decreased with time during the 35-day storage. There were no statistically significant differences in the activity of SOD between the groups until day 35 . The activity of SOD on day 35 in group UHF was statistically significant lower than

\begin{tabular}{|c|c|c|c|c|c|c|c|c|c|c|c|c|c|c|c|}
\hline \multirow[t]{2}{*}{ Time (day) } & \multicolumn{3}{|c|}{$\mathrm{pH}$} & \multicolumn{3}{|c|}{ LDH (U/I) } & \multicolumn{3}{|c|}{ Hemolysis rate $(\%)$} & \multicolumn{3}{|c|}{$\mathrm{K}^{+}(\mathrm{mM} / \mathrm{mL})$} & \multicolumn{3}{|c|}{$\mathrm{Na}^{+}(\mathrm{mM} / \mathrm{mL})$} \\
\hline & Control & $\begin{array}{c}\text { Group } \\
\text { HF }\end{array}$ & $\begin{array}{c}\text { Group } \\
\text { UHF }\end{array}$ & Control & $\begin{array}{c}\text { Group } \\
\text { HF }\end{array}$ & $\begin{array}{c}\text { Group } \\
\text { UHF }\end{array}$ & Control & $\begin{array}{c}\text { Group } \\
\text { HF }\end{array}$ & $\begin{array}{l}\text { Group } \\
\text { UHF }\end{array}$ & Control & $\begin{array}{c}\text { Group } \\
\text { HF }\end{array}$ & $\begin{array}{l}\text { Group } \\
\text { UHF }\end{array}$ & Control & $\begin{array}{c}\text { Group } \\
\text { HF }\end{array}$ & $\begin{array}{l}\text { Group } \\
\text { UHF }\end{array}$ \\
\hline 0 & 7.49 & 7.49 & 7.49 & 80.3 & 80.3 & 80.3 & 0.11 & 0.11 & 0.11 & 2.44 & 2.44 & 2.44 & 138.4 & 138.4 & 138.4 \\
\hline 7 & 7.27 & 7.27 & 7.25 & 137.5 & 140.2 & 139.2 & 0.29 & 0.29 & 0.29 & 20.45 & 20.9 & 21.0 & 132.4 & 131.9 & 131.7 \\
\hline 14 & 7.04 & 7.00 & 6.98 & 200.4 & 210.4 & 218.8 & 0.38 & 0.38 & 0.4 & 29.78 & 28.6 & 29.2 & 126.05 & 127.2 & 126 \\
\hline 21 & 6.92 & 6.92 & 6.88 & 263.7 & 275.8 & 277.8 & 0.5 & 0.48 & 0.52 & 35.6 & 34.6 & 36.2 & 121.0 & 122.4 & 120.8 \\
\hline 35 & 6.68 & 6.66 & 6.61 & 300.2 & 299.8 & 308.2 & 0.6 & 0.58 & $0.68^{*}$ & 39.7 & 40.2 & $41.8^{*}$ & 110.30 & 113.3 & 110.2 \\
\hline
\end{tabular}

Table 1: Effect of RFID on hemolysis rate, $\mathrm{pH}, \mathrm{LDH}$ activity, $\mathrm{K}^{+}, \mathrm{Na}^{+}$concentrations in stored units of $\mathrm{RBC}, \mathrm{n}=10\left({ }^{*} \mathrm{p}<0.05\right)$. 
Citation: Chabowska AM, Nędzi M, Lipska A, Rogowska A, Boczkowska-Radziwon B, et al. (2018) Ultrahigh Radio Frequency (820-960 MHz) Identification System Affects Antioxidant Barrier in Red Blood Cell Concentrates. J Blood Lymph 8: 213. doi:10.4172/2165-7831.1000213

control and group HF $(\mathrm{p}<0.05)$ (Figure 1B).The activity of GSH-Px has decreased in all groups of $\mathrm{RBC}$ units during storage. There were no statistically significant differences in the activity of GSH-Px between the groups until day 35. The activity of GSH-Px in group UHF on day 35 was statistically significant lower than in other groups (Figure 1C). Activity of GSSH-R has decreased during storage in all groups. Similar to other tested markers there were no statistically significant differences in the activity of GSSH-R between the groups until day 35 . Statistically significant lower activity of GSSH-R was noted in group UHF compare to other groups on the day 35 of storage (Figure 1D).

\section{Discussion}

The effect of electromagnetic radiation generated by RFID system on RBC quality has been investigated by several scientific groups. Kozma et al. [13] tested the impact of permanent exposure of $13,56 \mathrm{MHz}$ RFID on potassium, $\mathrm{pH}$, lactate, glucose, free hemoglobin and the hemolysis rate in $\mathrm{RBC}$ stored up to 42 days [8]. The observed biochemical changes remained within the normal expected values. They did not detect any obvious adverse effects of RFID on RBC. The similar investigations

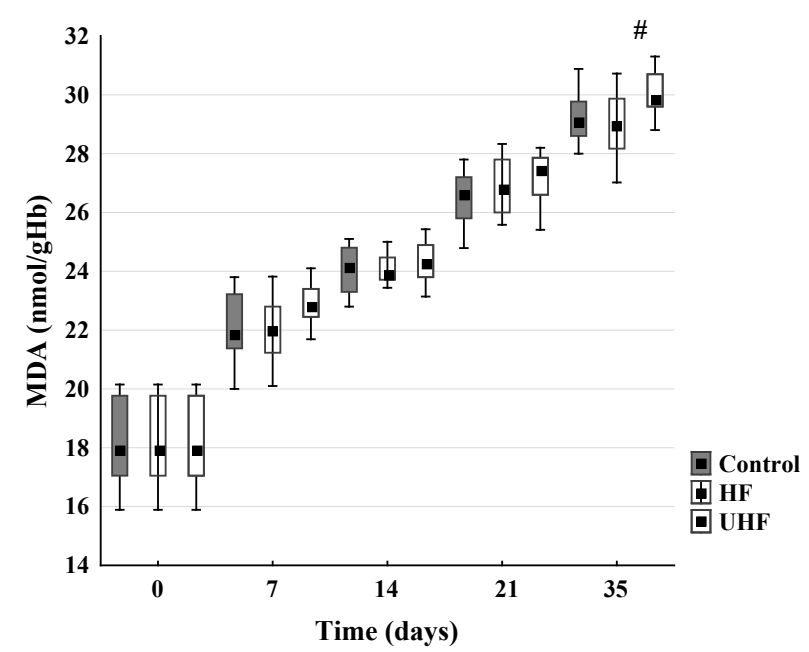

Figure 1A: The effect of RFID on lipid peroxidation and antioxidant enzyme activity in RBC. Malonyldialdehyde (MDA) concentration.

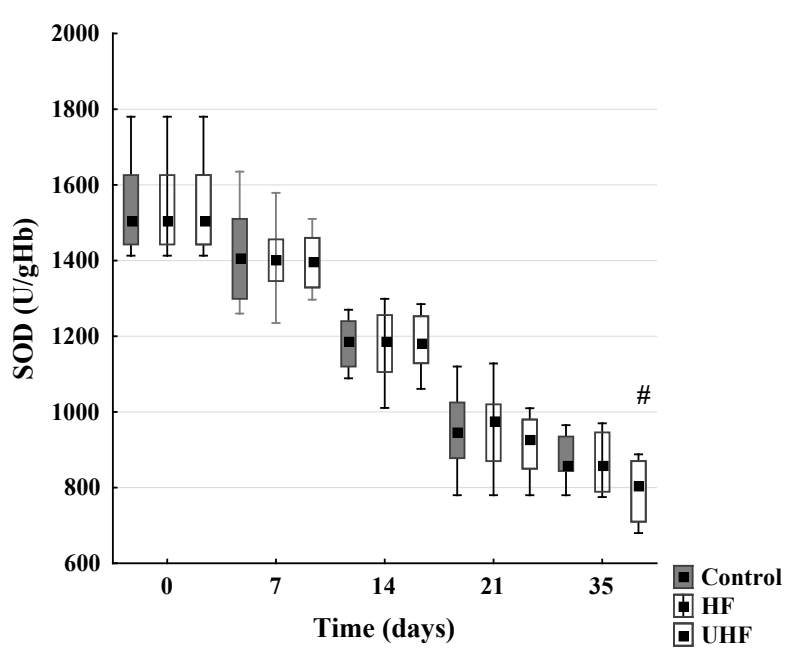

Figure 1B: Superoxide dismutase (SOD) activity .

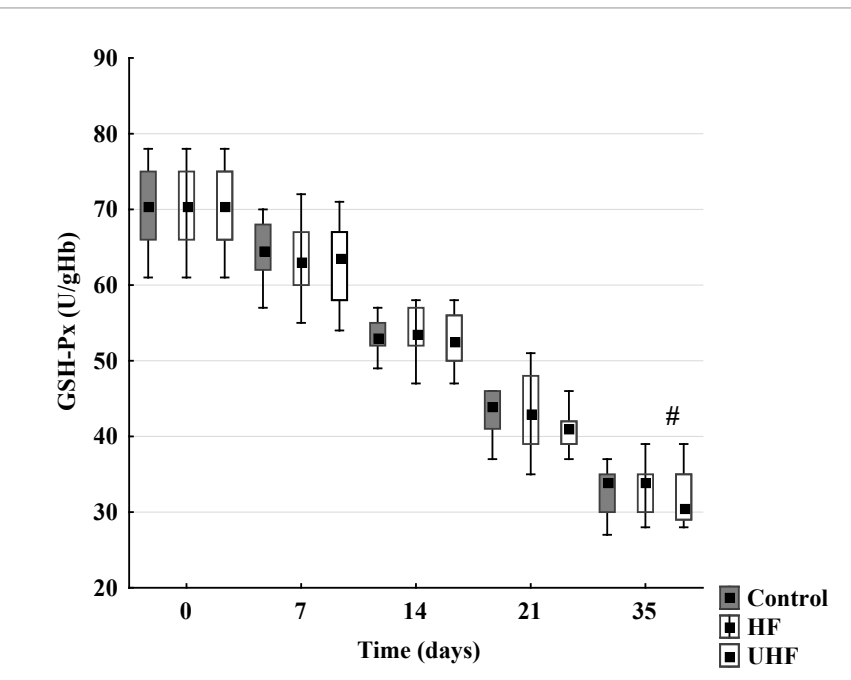

Figure 1C: Glutathione peroxidase (GSH-Px) activity.

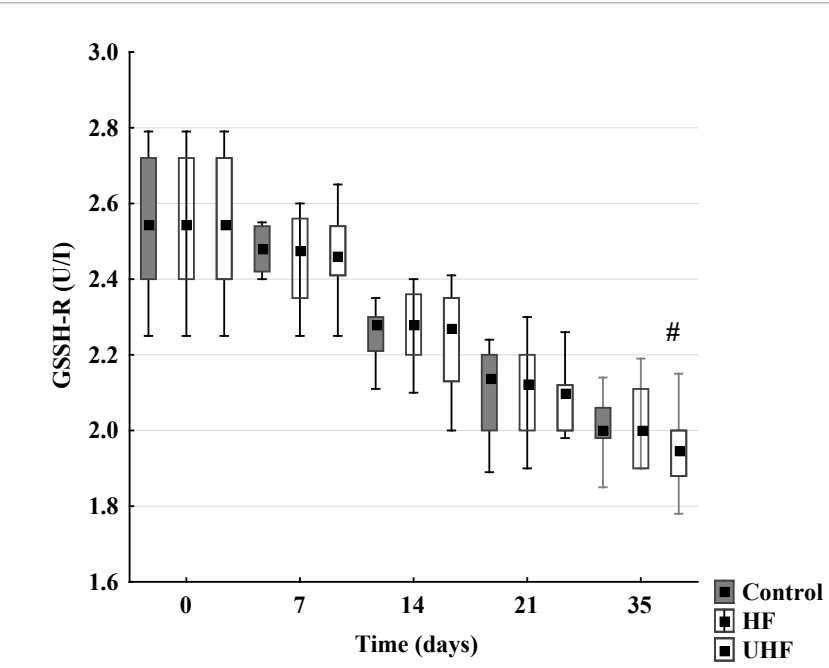

Figure 1D: Glutathione reductase (GSSH-R) activity in RBC: control $(n=10)$ group HF (13.5 MHz, $n=10)$ and group UHF $(820-960 \mathrm{MHz}, \mathrm{n}=10)$. Boxes indicate the upper and lower quartiles of the data and the bars indicate the median values. The whiskers indicate the minimum and maximum values. (NS-lack of statistical significance, \#-p<0.05).

conducted Davis et al. [14]. They also observed no notable changes in $\mathrm{RBC}$ count, $\mathrm{Hb}$, hematocrit, mean cell volume, $\mathrm{RBC}$ morphology score, free $\mathrm{Hb}$, and potassium or percent hemolysis in the 13, $56 \mathrm{MHz}$ RFID tagged RBC units versus control group. These studies had a significant limitation. No in vivo survival studies were performed, therefore, no comment can be made on whether prolonged exposure to radio waves used in RFID system affects RBC recovery or survival.

In our study the similar quality markers for RBC were also not significantly affected by constant exposure of $13,56 \mathrm{MHz}$ RFID system. However in RBC tagged with UHF RFID labels we observed statistically significant increased hemolysis rate and potassium release on the $35^{\text {th }}$ day of storage compare to units tagged with HF RFID. Wang et al. [15] also showed increase in free hemoglobin, potassium, and sodium in RBC exposed to UHF RFID but the differences to the control group did not reach statistical significance [10]. The clinical significance of the differences found in our study seems doubtful, as significant differences 
Citation: Chabowska AM, Nędzi M, Lipska A, Rogowska A, Boczkowska-Radziwon B, et al. (2018) Ultrahigh Radio Frequency (820-960 MHz) Identification System Affects Antioxidant Barrier in Red Blood Cell Concentrates. J Blood Lymph 8: 213. doi:10.4172/2165-7831.1000213

Page 5 of 5

shown are very minimal. It is less probable that it would really have effect on the clinical outcome of transfusion of components labelled by UHF tags.

These observed changes may be due to the fact that UHF waves can be absorbed by liquids and metals to bigger extent than HF waves. UHF waves are capable of exciting water molecules in blood products to the higher extent than HF waves and may cause increase in the temperature of blood component. It is less probably that the possible increase of temperature induced by radio waves of RFID system directly cause the higher susceptibility of erythrocytes to hemolysis.

Davis et al. [14] indeed proved that use of 13.56 $\mathrm{MHz}$ RFID technology is unlikely to have any significant temperature or biologic effects on RBC and plasma units under normal operating conditions [9].

We hypothesize that the energy of radio waves may have an influence on the generation of reactive oxygen species (ROS) and/or activity of anioxidants of erythrocytes. It is known that electromagnetic fields increase free radical activity in cells [11-13]. It is rather due to stimulation of ROS production than inhibiting antioxidant enzyme activity. Radio frequency electromagnetic radiation has been shown to stimulate NADH oxidase in the plasma membranes of mammalian cells which increases ROS formation [14].

Continuous neutralization of ROS by antioxidants may exceed their scavenging capacity and lead to oxidative stress [15]. Studies have demonstrated that radio waves may induce oxidative stress or apoptosis in animal tissues [16-18]. According to our knowledge this is the first study presenting effect of radio waves generated in RFID system on antioxidants and lipid peroxidation in RBC. We found that UHF but not HF waves applied in RFID system caused statistically significant decrease of SOD, GSH-Px, GSSH-R activity and increase of MDA production in RBC stored for 35 days. It may be at least one of the mechanisms behind increased hemolysis noted in these erythrocytes on $35^{\text {th }}$ day of storage [19-23].

No laboratory findings are available to support the idea that the exposure to high levels of HF radio waves on RBC components could have negative effect on the maintenance of oxidoreductive balance of stored red blood cell components. In contrary UHF RFID tags affect this balance and may lead to eryptosis. The clinical significance of the differences found in our study seems doubtful, as significant differences shown are very minimal. It is less probable that it would really have effect on the clinical outcome of transfusion of components labelled by UHF tags.

In spite of the advantages of UHF over HF waves system the approval of UHF RFID system for blood components needs further studies.

\section{Acknowledgment}

We thank Mr. Grzegorz Piestrak, Manager, M2M company, Warsaw, Poland for providing of RFID systems and for assistance in performing our experiments.

\section{Conflict of Interest}

All authors have disclosed no conflict of interest.

\section{References}

1. Davis R, Geiger B, Gutierrez A, Heaser J, Veeramani D (2009) Tracking blood products in blood centres using radio frequency identification: a comprehensive assessment. Vox Sang 97: 50-60.

2. Hohberger C, Davis R, Briggs L, Gutierrez A, Veeramani D (2012) Applying radio-frequency identification (RFID) technology in transfusion medicine. Biologicals 40: 209-213.

3. Kabachinski J (2005) An introduction to RFID. Biomed Instrum Technol 39 131-134.

4. Knels R, Ashford P, Bidet F, Böcker W, Briggs L, et al. (2010) Guidelines for the use of RFID technology in transfusion medicine.Task Force on RFID of the Working Party on Information Technology; International Society of Blood Transfusion. Vox Sang 98: 1-24.

5. (2005) Radio-frequency identification: its potential in healthcare. Health Devices 34: 149-160.

6. Hohberger C, Davis R, Briggs L, Gutierrez A, Veeramani D (2012) Applying radio-frequency identification (RFID) technology in transfusion medicine. Biologicals 40: 209-213.

7. Uysal I, Hohberger C, Rasmussen RS, Ulrich DA, Emond JP, et al. (2012) Effects of radio frequency identification-related radiation on in vitro biologics. PDA J Pharm Sci Technol 66: 333-345.

8. Monahan T (2006) Radio frequency identification (RFID). In: Staples WG (Editor), Encyclopedia of Privacy, Greenwood Press, Westport, CT, pp: 455-456.

9. Buege JA, Aust SD (1978) Microsomal lipid peroxidation. Methods Enzymol 52: 302-310.

10. Sykes JA, McCormack FX, O'Brien TJ (1978) A preliminary study of superoxide dismutase content of some human tumors. Cancer Res 38: 2759-2762.

11. Paglia DE, Valentine WN (1967) Studies on quantative and qualitive characterization of erythrocyte glutathione peroxidase. J Lab Clin Med 70: 158169

12. Mize CE, Landgon RG (1962) Hepatic glutathione reductase I. Purification and general kinetic properties. J Biol Chem 237: 1589-1595.

13. Kozma N, Speletz H, Reiter U, Lanzer G, Wagner T (2011) Impact of 13.56$\mathrm{MHz}$ radiofrequency identification systems on the quality of stored red blood cells. Transfusion 51: 2384-2390.

14. Davis R, Gottschall J, Gutierrez A, Hohberger C, Veeramani D, et al. (2012) Absence of acute adverse in-vitro effects on AS-1 red blood cells and whole blood derived platelets following prolonged exposure to $13.56 \mathrm{MHz}$ radio energy. Transfusion 52: 2030-2042.

15. Wang QL, Wang XW, Zhuo HL, Shao CY, Wang J, et al. (2013) Impact on storage quality of red blood cells and platelets by ultrahigh-frequency radiofrequency identification tag. Transfusion 53: 868-871.

16. Mailankot M, Kunnath AP, Jayalekshmi H, Koduru B, Valsalan R (2009) Radio frequency electromagnetic radiation (RF-EMR) from gsm $(0.9 / 1.8 \mathrm{ghz})$ mobile phones induces oxidative stress and reduces sperm motility in rats. Clinics 64 561-565.

17. Grundler W, Kaiser F, Keilmann F, Walleczek J (1992) Mechanisms of electromagnetic interaction with cellular systems. Naturwissenschaften 79 : 551-559.

18. Lupke M, Rollwitz J, Simkó M (2004) Cell activating capacity of 50 Hz magnetic fields to release reactive oxygen intermediates in human umbilical cord bloodderived monocytes and in Mono Mac 6 cells. Free Radic Res 38: 985-993.

19. Friedman J, Kraus S, Hauptman Y, Schiff Y, Seger R (2007) Mechanism of short-term ERK activation by electromagnetic fields at mobile phone frequencies. Biochem J 405: 559-568.

20. Jozwik M, Jozwik M, Szczypka M, Szczypka M, Gajewska J, et al. (1997) Antioxidant defense of red blood cells and plasma in stored human blood. Clin Chim Acta 267: 129-142.

21. Oktem F, Ozguner F, Mollaoglu H, Koyu A, Uz E (2005) Oxidative damage in the kidney induced by $900-\mathrm{MHz}-\mathrm{emitted}$ mobile phone: protection by melatonin. Arch Med Res 36: 350-355.

22. Oral B, Guney M, Ozguner F, Karahan N, Mungan T, et al. (2006) Endometria apoptosis induced by a $900-\mathrm{MHz}$ mobile phone: preventive effects of vitamins E and C. Adv Ther 23: 957-973.

23. Ozguner F, Bardak Y, Comlekci S (2006) Protective effects of melatonin and caffeic acid phenethyl ester against retinal oxidative stress in long-term use of mobile phone: a comparative study. Mol Cell Biochem 282: 83-88. 